\title{
Use of spinal anaesthesia in neonates and infants in Antananarivo, Madagascar: a retrospective descriptive study
}

\author{
Harifetra M. R. Randriamizao', Aurélia Rakotondrainibe ${ }^{1,5^{*}}$ (D) Lova D. E. Razafindrabekoto², \\ Prisca F. Ravoaviarivelo ${ }^{3}$, Andriambelo T. Rajaonera' and Mamy L. Andriamanarivo ${ }^{4}$
}

\begin{abstract}
Objective: The aim of this study was to present the first cases of spinal anesthesia, in newborns and infants, preterm/ ex-prematures, in order to determine its feasibility and its potential harmlessness, in Antananarivo-Madagascar. Indeed, spinal anesthesia is a low cost technique and can limit respiratory complications, postoperative apnea a contrario with pediatric general anesthesia which can lead to perioperative risks.

Results: In a retrospective, descriptive, 7-year (2013 to 2019) period study, conducted in the University Hospital Joseph Ravoahangy Andrianavalona, 69 patients' data files planned to have spinal anesthesia were recorded. These pediatric patients were predominantly male (sex ratio $=2.8$ ) and 37 [28-52] days old. The smallest anesthetized child weighed $880 \mathrm{~g}$; the youngest was 4 days old. Twenty-seven (27) of them were premature and 20.3\% presented respiratory diseases. They were mostly scheduled for hernia repair (90\%). Spinal anesthesia was performed, with a Gauge 25 Quincke spinal needle, after 2 [1-2] attempts with hyperbaric bupivacaine of 4 [3.5-4] mg. Failure rate was 5.8\%. The heart rate was stable throughout perioperative period and no complications were observed.
\end{abstract}

Keywords: Spinal anesthesia, Newborns, Infants, Preterm, Ex prematures, Madagascar

\section{Introduction}

Spinal anesthesia (SA) is a part of anesthesia for sub umbilical and lower limb surgeries [1]. The first spinal anesthesia in children had been practiced by Bier in the nineteenth century (1898), then by Bainbridge (1901) and Gray (1909) [1, 2]. Due to considerable improvements of general anesthesia (GA) in the middle of twentieth century, this regional anesthesia was abandoned [2]. In 1990-2000, spinal anesthesia in newborns or in preterm had an upsurge of 2.1 to $3.6 \%$ in regional anesthesia after the decline of caudal anesthesia practice $[3,4]$. Nowadays, SA tends to be mainly performed in pediatric anesthesia, up to $95.4 \%$ of children, as much in the newborns as in the preterm $[1-3,5]$. SA allows the prevention and the reduction of perioperative complications even if its duration is an important limiting factor $[1-3,6]$. Because of this limitation, short surgery is the most indicated under SA $[1,5,7]$. For more efficiency, this technique should be performed by experimented anesthetists $[1,8]$.

In Antananarivo-Madagascar, at the Hospital University of JR Andrianavalona (CHU JRA), spinal anesthesia has been performed since 2013. The aim of this study is to present the first cases of spinal anesthesia, in newborns and infants, preterm / ex-prematures, in order to

*Correspondence: aaurelia.rakotondrainibe@gmail.com

1 Department of Anesthesia and Intensive Care, University

of Antananarivo, Antananarivo, Madagascar

Full list of author information is available at the end of the article

(c) The Author(s) 2020. This article is licensed under a Creative Commons Attribution 4.0 International License, which permits use, sharing, adaptation, distribution and reproduction in any medium or format, as long as you give appropriate credit to the original author(s) and the source, provide a link to the Creative Commons licence, and indicate if changes were made. The images or other third party material in this article are included in the article's Creative Commons licence, unless indicated otherwise in a credit line to the material. If material is not included in the article's Creative Commons licence and your intended use is not permitted by statutory regulation or exceeds the permitted use, you will need to obtain permission directly from the copyright holder. To view a copy of this licence, visit http://creativeco mmons.org/licenses/by/4.0/. The Creative Commons Public Domain Dedication waiver (http://creativecommons.org/publicdomain/ zero/1.0/) applies to the data made available in this article, unless otherwise stated in a credit line to the data. 
determine its feasibility and its potential harmlessness, in Antananarivo.

\section{Main text \\ Methods \\ Study design}

A retrospective, descriptive study was conducted on the data files from scheduled pediatric surgeries under spinal anesthesia. The study was conducted, in the operating theater of the CHU JRA, from 2013 to 2019. This latter is the surgical reference center of Madagascar, particularly in pediatric surgery.

This observational, retrospective study conducted in operating theater had the approval of the University Hospital Joseph Ravoahangy Andrianavalona and the Department of Anesthesia and Resuscitation of the Faculty of Medicine of Antananarivo.

During the perioperative procedures, the general anesthesia risks and modalities of spinal anesthesia were explained to the patients' parents, during the anesthesia consultation (AC). Their written informed consent was obtained for the anesthesia and surgery and included in the anesthesia file. The AC was carried out and validated by anesthesiologists (also the performers of the SA) who had prior training about SA in small children.

\section{Anesthesia procedures}

The lumbar puncture was considered successful when the cerebrospinal fluid (CSF) flowed back. Then, the patient was placed in a $45^{\circ}$ tilt-head up. The local anesthetic (LA) used was hyperbaric $0.5 \%$ bupivacaine $(1 \mathrm{mg} / \mathrm{kg}=0.2 \mathrm{~mL} / \mathrm{kg})$. Spinal anesthesia was considered successful, when the patient no longer moved his lower limbs or had anal sphincter relaxation; and also when GA conversion or complementary local anesthesia (by the surgeon) throughout the surgical procedure was not required. When spinal anesthesia succeeded, a pacifier dipper with sugar water was given to the baby.

\section{Studied parameters and variables}

The studied variables and parameters were (i) gender, (ii) perinatal parameters: weeks at birth, prematurity (with causes), birth weight, (iii) parameters during the AC: age (in days), postconceptual age (in corrected weeks $[\mathrm{CW}]$ for preterm or ex prematures), and weight, (iv) spinal anesthesia parameters: procedure of

Table 1 Population study characteristics

\begin{tabular}{|c|c|c|c|}
\hline & & $\mathbf{N}$ & $\%$ \\
\hline \multirow[t]{2}{*}{ Pediatric patients } & Newborns & 18 & 26.0 \\
\hline & Infants & 51 & 73.9 \\
\hline Preterm or ex-prematures & & 27 & 39.1 \\
\hline \multirow[t]{7}{*}{ Weight at the anesthesia consultation (g) } & $<1000$ & 1 & 1.4 \\
\hline & {$[1000-2000[$} & 2 & 2.9 \\
\hline & {$[2000-3000[$} & 17 & 24.6 \\
\hline & {$[3000-4000[$} & 24 & 34.8 \\
\hline & {$[4000-5000[$} & 16 & 23.2 \\
\hline & {$[5000-6000[$} & 7 & 10.1 \\
\hline & $\geq 6000$ & 2 & 1.4 \\
\hline \multirow[t]{4}{*}{ Medical history } & Respiratory diseases $^{\mathrm{a}}$ & 14 & 20.3 \\
\hline & Resuscitation at birth & 3 & 4.3 \\
\hline & Incubator after birth & 6 & 8.7 \\
\hline & Others $^{b}$ & 3 & 4.3 \\
\hline \multirow[t]{8}{*}{ Causes of prematurity } & Anamnios or Oligoamnios & 4 & 5.8 \\
\hline & $\begin{array}{l}\text { Gestational diabetes and/or pregnancy- } \\
\text { induced hypertension }\end{array}$ & 8 & 11.6 \\
\hline & Pre-eclampsia or Eclampsiac ${ }^{c}$ & 6 & 8.7 \\
\hline & Maternal fetal infections & 4 & 5.8 \\
\hline & Placenta prævia & 1 & 1.4 \\
\hline & Twin pregnancy & 1 & 1.4 \\
\hline & PROM $^{d}+$ cord prolapse & 1 & 1.4 \\
\hline & Fetal anoxia ${ }^{c}$ & 2 & 2.9 \\
\hline
\end{tabular}

a Respiratory diseases = meconial amniotic fluid inhalation at birth, bronchiolitis; ${ }^{\mathrm{b}}$ Others = intrauterine growth restriction (IUGR), neonatal infection, gastroesophageal reflux; ${ }^{c} \pm$ other conditions (preeclampsia, twin pregnancy); ${ }^{d} \mathrm{PROM}=$ premature rupture of fetal membranes 
Table 2 Perioperative characteristics

\begin{tabular}{|c|c|c|c|}
\hline & & $\mathbf{N}$ & $\%$ \\
\hline \multirow[t]{6}{*}{ Surgery } & Hernia (inguinal and/or scrotal) \pm circumcision & 50 & 72.5 \\
\hline & Bilateral hernia & 26 & 37.7 \\
\hline & Right hernia & 16 & 23.2 \\
\hline & Left hernia & 8 & 11.6 \\
\hline & Bilateral ovarian hernia & 19 & 27.5 \\
\hline & Surgery of lower limbs (gangrene/necrosis) & 2 & 2.9 \\
\hline \multirow[t]{14}{*}{ Spinal anesthesia (SA) } & Position of the patient & & \\
\hline & Lateral decubitus & 9 & 13.0 \\
\hline & Sitting position & 60 & 87.0 \\
\hline & Number of punctures & & \\
\hline & 1 & 34 & 47.3 \\
\hline & 2 & 22 & 31.9 \\
\hline & $\geq 3$ & 13 & 18.8 \\
\hline & Incidents during the technique (blood reflux) & & \\
\hline & CSF reflux after a first blood reflux & 1 & 1.4 \\
\hline & CSF reflux after a 2nd puncture & 4 & 5.8 \\
\hline & Failure of SA & & \\
\hline & Due to the technique $\mathrm{a}^{\mathrm{a}}$ & 2 & \\
\hline & Due to the LA & 2 & 2.9 \\
\hline & General anesthesia (GA) conversion & 4 & $\begin{array}{l}5.8 \\
2.9\end{array}$ \\
\hline
\end{tabular}

CSF:Cerebral Spinal Fluid; LA: Local Anesthetic; GA: General Anesthesia

${ }^{a}$ Blood reflux without secondary CSF reflux or after 2nd lumbar puncture

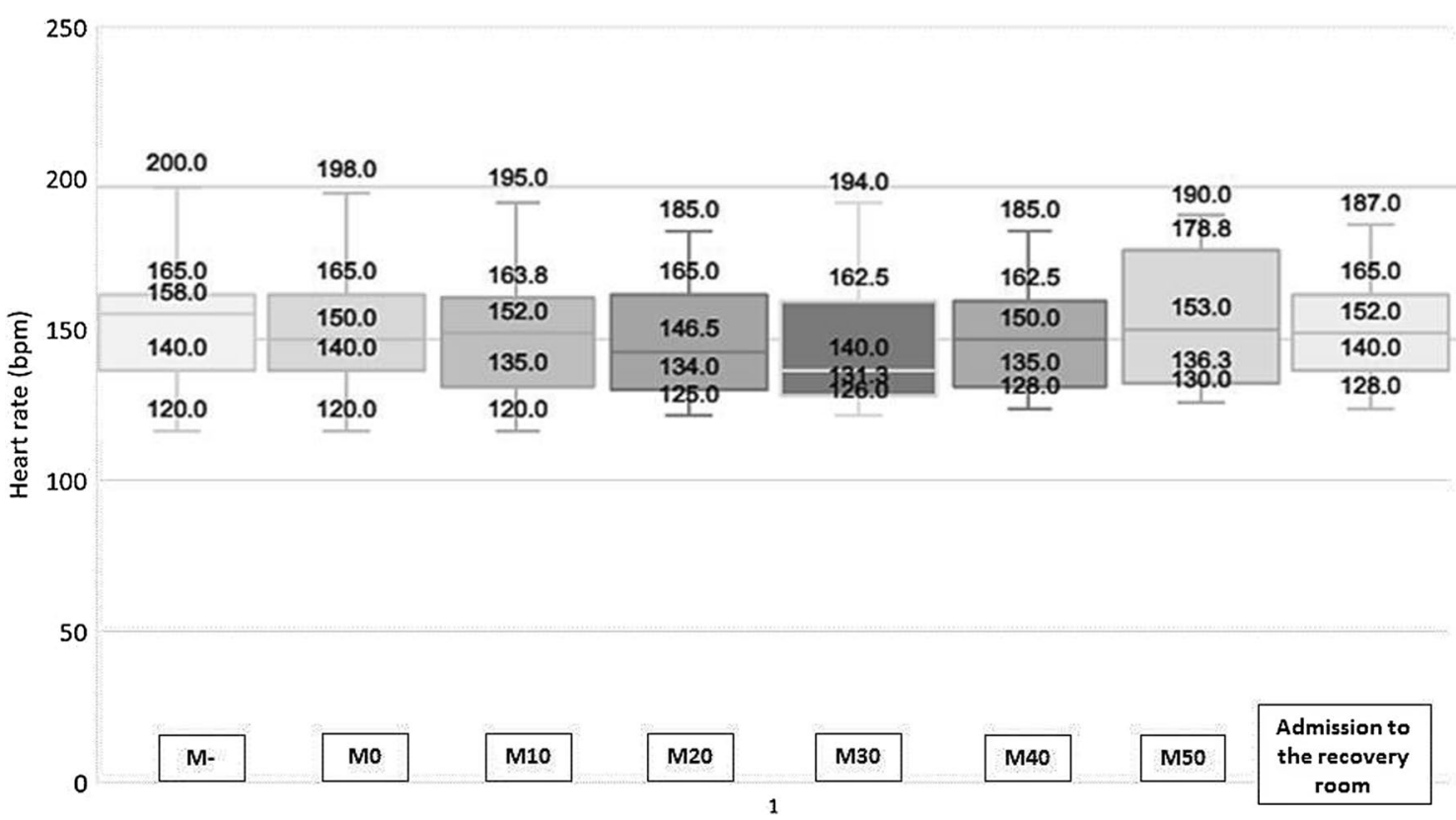

Fig. 1 Perioperative heart rate of the patients under spinal anesthesia (expressed in median, interquartile 25\%-75\%, minimum and maximum). bpm = beat per minute; $M=$ minute; $M-=$ heart rate before $S A$ 
lumbar puncture and spinal anesthesia, (v) perioperative variables: complementary procedures during SA, surgery characteristics, length of stay in the postoperative recovery room and (vi) perioperative heart rate.

\section{Presentation of data}

The continuous variables are expressed in median [interquartile 25\%-75\%] and the categorical variables in frequencies.

\section{Results}

Over the 7-years period, 69 SA were indicated (Additional file 1: Figure S1: Spinal anesthesia procedureCHU JRA) in predominantly male (sex ratio $=2.8)$ and 37 [28-52] days old patients (Table 1). The smallest patient weighed $880 \mathrm{~g}$ and the youngest was 4 days old. The patients weighed 2400 [1995-3025] g at birth and 3450 [2800-4240] g on the AC day. Twenty-seven patients were preterm, aged 33 [27-37] weeks at birth and with a corrected age of 40.5 [37-42] CW on the anesthesia day. Fourteen children $(20.3 \%)$ had a medical history of respiratory diseases. The intervention was performed $5[3,4]$ days after the AC. The main surgery indications (Table 2) were hernias and surgical procedure was 27.5 [17.5-40.0] minutes ranging from 10 to $65 \mathrm{~min}$. For all patients, perioperative perfusion was performed with a G24 intravenous catheter. The lumbar puncture was performed on a curved back patient, in a sitting or lateral decubitus (if sedated) position, by a trained nurse anesthetist. The puncture was performed at the intersection point between the line connecting the highest point of both iliac crests and the vertebral axis. The localization of lumbar puncture was determined by palpation, by the SA performer. The material used was an $80 \mathrm{~mm}-$ G25 Quincke spinal needle (the thinnest needle available at the CHU JRA). Inhaled sedation was needed in $13.0 \%$, when positioning patient was difficult. Number of punctures was $2[1,2]$ attempts. A dose of 4 [3.5-4] mg hyperbaric $0.5 \%$ was administered. The lumbar puncture was successful in $97.1 \%$ and spinal anesthesia in $94.2 \%$. No complementary local anesthesia by the surgeon was required. The GA conversion was $5.8 \%$ when SA failed.

The heart rates were slight constant throughout the intervention until admission to the recovery room (Fig. 1). The patients stayed in postoperative recovery room during 70 [60-120] minutes. No perioperative complications were observed.

\section{Discussion}

In the present study, spinal anesthesia was scheduled for 69 babies. This series represents the first pediatric spinal anesthesia, performed since 2013, in
Madagascar (Additional file 2: Data and materials). In developed countries, such as in the United States, SA has been included since 1977, with 262 SA, on less than 1-year patients, in 15 years [9]. Williams et al. [5] reported 95.4\% pediatric spinal anesthesia. In Europe, 400 to $500 \mathrm{SA}$ are performed annually, (18\% in preterm and $5 \%$ newborns) $[3,10]$. In other countries, like India, in a 1-year period study, 102 children (from 6 months to 14 years) received spinal anesthesia for sub umbilical and lower limb orthopedic surgeries [6]. In low-income countries, few studies on pediatric spinal anesthesia have been related. Ela A.A. et al. [11], in Cameroon, report a series of 55 children operated under spinal anesthesia. However, the use of spinal anesthesia especially in "precarious" or "difficult" situations is attractive because it requires fewer perioperative resources [12].

Spinal anesthesia in the present study was performed, even at very young age (27 preterm) and low weight patients, and 14 children had a medical history of respiratory diseases. Spinal anesthesia is primarily indicated when general anesthesia presents a high risk (= respiratory complications or postoperative apnea because of pulmonary disease or prematurity) $[1,7,10,13]$. SA is the "gold standard" technique in preterm (gestational age $\leq 37$ weeks) and high-risk patients (preterm infants with postconceptual age $<60 \mathrm{CW}$ ) [2, 9]. Indeed, this population is at high risk of postoperative apnea, especially if general anesthesia is performed. Spinal anesthesia is a safe alternative when tracheal intubation should be avoided (due to bronchopulmonary dysplasia or respiratory diseases ...) $[1,4]$. Indeed, spinal anesthesia can reduce or avoid apnea $[9,10]$. Also, SA causes minimum respiratory complications $[2,10,14,15]$. In this study, most of the patients had respiratory diseases $(20.3 \%$ rhino-bronchitis) and $39.1 \%$ were premature. In the present study, all these facts motivated spinal anesthesia. In addition, patients' characteristics were quite similar to a study by Hermanns et al. [13]: 34.5 (24-40) weeks at birth, 10 (5-24) weeks postnatal age at the time of the intervention, and $3.5(2.2-5.2) \mathrm{kg}$ in weight.

The surgeries (lasting 27.5 [17.5-40.0] $\mathrm{min}$ ), in the present study, were mostly hernia repairs. Spinal anesthesia is the gold standard for lower abdominal and lower limbs surgeries under 90 min duration $[1,2,5,7]$. This was similar to a study of Ela et al. [11] (from 25 to $78 \mathrm{~min}$ ) and shorter than results in a study of Frumiento et al. [9] (48 [15-130] $\mathrm{min})$. The most concerned surgeries are inguinal hernia repair $[1,2,5,7]$. But other surgeries (resection of ileostoma, sacral teratoma ...) can also be performed under SA $[11,13]$.

The spinal puncture $(2[1,2]$ attempts) was performed in sitting or lateral position, in the intersection point between the line connecting the highest point of both 
iliac crests (Tuffier's line) and the vertebral axis, with an $80 \mathrm{~mm}-\mathrm{G} 25$ Quincke spinal needle. This midline approach is the most used in SA in small children, in lateral or seated position $[6,13,16]$. A $25 \mathrm{G}$ pencil-point needle such Whitacre (avoiding post lumbar puncture headache) or $25 \mathrm{G}$ neonatal spinal needle are recommended $[11,13]$. These types of needles are not available in the CHU JRA, so 25G Quincke spinal needle was used for all patients.

Hyperbaric bupivacaine $0.5 \%$ was used with a dose of 4 [3.5-4] mg. The most used local anesthetics are tetracaine $0.5 \%$ and bupivacaine $0.5 \%$ lasting 90 to $120 \mathrm{~min}$ [1]. Hyperbaric bupivacaine $(0.5 \%)$ is mostly used in a dose from 0.3 to $1 \mathrm{mg} / \mathrm{kg}[1,6,13,17]$.

In the present study, for all patients, 2 anesthetists who had prior training on this technique performed the SA to limit performance bias. Even the spinal anesthesia can be performed by either an anesthetist-intensivist, or an anesthesia-intensivist trainee, or a state-certified nurse anesthetist, SA performer should be well trained for the technique [11]. Trainees in anesthesia have a significant different success rate compared to anesthesiologists $(83 \%$ versus $98.9 \%$ ); the failure rate is $28 \%$ and the risk of total spinal anesthesia is approximately 0.63 to $0.8 \%$, if the performer is not trained $[1,5]$.

The success of the lumbar puncture was $97.1 \%$ after 2 $[1,2]$ attempts and SA success was $94.2 \%$. Since the Bromage score is not assessable among this pediatric population, the success of the spinal anesthesia is estimated and based on the sudden loss of leg movement while normal tonus in the arms and/or the relaxation of the anal sphincter and the possibility of performing the surgical procedure [14, 18]. Williams et al. [5] reported a success rate of $97.4 \%$, quite similar with our results. In the present study, no complementary local anesthesia by the surgeon was required and the GA conversion was $5.8 \%$. This failure rate was similar to literature, varying from 1.04 to $24.6 \%$ [7, 9, 17, 19]. Dohms et al. [19] find a failure rate of $7.5 \%$ and $16 \%$ required supplemental anesthesia, also more than two punctures were needed in $28 \%$. In Kachko et al's [7] study, conversion to general anesthesia was $1.04 \%$. In inguinal hernia repair, Frumiento et al. [9] describe $91.4 \%$ of adequate spinal anesthesia, $78.6 \%$ no supplemental anesthesia, $4.5 \%$ complementary local anesthesia and $2.2 \%$ general anesthesia conversion.

The heart rates were stable throughout the perioperative period. Spinal anesthesia allows remarkable cardiovascular stability and can avoid bradycardia with minimum cardiac complications $[2,8,10,14,15,18]$. But in some cases, $1.5 \%$ patients experienced bradycardia in the operating room, and $1.9 \%$ received vagolytics [9].

Spinal anesthesia offers a good balance between safety and perioperative risks and appears to be a safe technique, provided that the contraindications are respected; the frequency of complications is $30 \%[1,5$, 10, 15]. SA causes less bradycardia, apnea, desaturation, requiring postoperative respiratory assistance than GA; ventilation and oxygenation are not generally compromised, even in patients at high risk $[8,18,20]$. In the present study, no perioperative complications were observed.

In Antananarivo, this series is the first to have been reported. The strength of this study is the characteristics of the population (preterm, newborns, and infants).

\section{Conclusion}

Spinal anesthesia can be performed on small pediatric patients, even on very young and very low-weight patient. Hernia repair was the most concerned surgery under spinal anesthesia which had a high success rate and no consequent complications. These first cases should motivate a wider and more frequent practice in Antananarivo, Madagascar.

\section{Limitations}

The monocentric and retrospective characteristic of this study are the main limits; the presented results do not reflect the whole Malagasy population.

\section{Supplementary information}

Supplementary information accompanies this paper at https://doi. org/10.1186/s13104-020-05330-9.

Additional file 1: Figure S1. Spinal anesthesia procedure at the $\mathrm{CHU}$ JRA (A: Materials used = hyperbaric bupivacaine, $1 \mathrm{~mL}$ syringe, Q25G spinal needle; B: Sitting position; C: Lateral decubitus position; D: Lumbar puncture).

Additional file 2. Data and materials

\section{Abbreviations}

AC: Anesthesia consultation; bpm: Heart beat per minute; CHU JRA: Centre Hospitalier Universitaire Joseph Ravoahangy Andrianavalona; CSF: Cerebrospinal fluid; CW: Corrected weeks; G: Gauge; GA: General anesthesia; IUGR : Intrauterine growth restriction; kg: Kilogram; LA: Local anesthetic; mg: Milligrams; mL: Milliliters; PROM: Premature rupture of fetal membranes; SA: Spinal anesthesia.

\section{Acknowledgements}

Not applicable

\section{Authors' contributions}

HMRR, AR: study instigators, redaction, data analysis, anesthesia performers. LDER: bibliographic research. PFR: data collection and anesthesia assistant. ATR: revision and approval. MLA: final revision and approval. All authors read and approved the final manuscript.

Funding

No funding for this study.

Availability of data and materials

Data and materials are available (excel) Additional file 2. 


\section{Ethics approval and consent to participate:}

The indication of the spinal anesthesia was approved by the CHUJRA and head department.The parents of anesthetized patients were informed of the SA and gave their consent before the realization of the surgical and anesthesia procedure.

\section{Consent for publication}

All the authors consent for publication, all patients'data were anonymously analyzed.

\section{Competing interests}

The authors declare that they have no competing interests.

\section{Author details}

${ }^{1}$ Department of Anesthesia and Intensive Care, University of Antananarivo, Antananarivo, Madagascar. ${ }^{2}$ Department of Anesthesia and Intensive Care, University of Fianarantsoa, Fianarantsoa, Madagascar. ${ }^{3}$ Department of Anesthesia and Intensive Care - Operating Theater, CHU Joseph Ravoahangy Andrianavalona, Antananarivo, Madagascar. ${ }^{4}$ Department of Pediatric Surgery, University of Antananarivo, Antananarivo, Madagascar. ${ }^{5}$ Surgical Intensive Care, CHU Joseph Ravoahangy Andrianavalona, BP 4150 - 101, Antananarivo, Madagascar.

Received: 10 June 2020 Accepted: 9 October 2020

Published online: 21 October 2020

\section{References}

1. Lopez T, Sanchez FJ, Garzon JC, Muriel C. Spinal anesthesia in pediatric patients. Minerva Anestesiol. 2012;78(1):78-87.

2. Gupta A, Saha U. Spinal anesthesia in children: a review. J AnaesthesiolClinPharmacol. 2014;30(1):10-8.

3. Frawley G, Ingelmo P. Spinal anaesthesia in the neonate. Best Pract Res ClinAnaesthesiol. 2010:24(3):337-51.

4. Nickel US, Meyer RR, Brambrink AM. Spinal anesthesia in an extremely low birth weight infant. PaediatrAnaesth. 2005;15(1):58-62.

5. Williams RK, Adams DC, Aladjem EV, Kreutz JM, Sartorelli KH, Vane DW, et al. The safety and efficacy of spinal anesthesia for surgery in infants: the Vermont infant spinal registry. AnesthAnalg. 2006;102(1):67-71.

6. Verma D, Naithani U, ChayenikaGokula H. Spinal anesthesia in infants and children: a one year prospective audit. Anesth Essays Res. 2014;8(3):324-9.

7. Kachko L, Simhi E, Tzeitlin E, Efrat R, Tarabikin E, Peled E, et al. Spinal anesthesia in neonates and infants-a single-center experience of 505 cases. PaediatrAnaesth. 2007;17(7):647-53.
8. Gerber AC, Weiss M. Awake spinal or caudal anesthesia in preterm for herniotomies: what is the evidence based benefit compared with general anesthesia? CurrOpinAnesthesiol. 2003;16(3):315-20.

9. Frumiento C, Abajian C, Vane DW. Spinal anesthesia for preterm infants undergoing inguinal hernia repair. Arch Surg. 2000;135(4):445-51.

10. Kokki H. Spinal blocks. PaediatrAnaesth. 2012;22(1):56-64.

11. Ela AA, Ngayap G, Owono Etoundi P, Esiene A, Bengono R, Mikone A. La rachianesthésie chez l'enfant : bilan d'une année d'expérience à l'Hôpital Central de Yaoundé. Health Sci Dis 2013; 14(4).

12. Komorowski M, Fleming S, Mawkin M, Hinkelbein J. Anaesthesia in austere environments: literature review and considerations for future space exploration missions. Npj Microgravity. 2018;4(1):1-11.

13. Hermanns H, Stevens MF, Werdehausen R, Braun S, Lipfert P, JetzekZader M. Sedation during spinal anesthesia in infants. Br J Anaesth. 2006;97(3):380-4.

14. Suresh S, Hall SC. Spinal anesthesia in infants: is the impractical practical? AnesthAnalg. 2006;102(1):65-6.

15. Kurth CD, Coté CJ. Postoperative apnea in former preterm infants. General anesthesia or spinal anesthesia-do we have an answer? Anesthesiology. 2015;123(1):15-7.

16. Jung JY, Kim EH, Song IK, Lee JH, Kim HS, Kim JT. The influence of age on positions of the conusmedullaris, Tuffier's line, dural sac, and saccrococcygeal membrane in infants, children, adolescents, and young adults. PaediatrAnaesth. 2016:26(12):1172-8.

17. Seyedhejazi M, Moghadam A, Sharabiani BA, Golzari SE, Taghizadieh N. Success rates and complications of awake caudal versus spinal block in preterm infants undergoing inguinal hernia repair: a prospective study. Saudi J Anaesth. 2015;9(4):348-52.

18. Tirmizi H. Spinal anesthesia in infants: recent developments. CurrOpinAnesthesiol. 2015;28(3):333-8.

19. Dohms K, Hein M, Rossaint R, Coburn M, Stoppe C, Ehret CB, et al. Inguinal hernia repair in preterm neonates: is there evidence that spinal or general anesthesia is the better option regarding intraoperative and postoperative complications? A systematic review and meta-analysis. BMJ Open. 2019;9(10):e028728.

20. Jones LJ, Craven PD, Lakkundi A, Foster JP, Badawi N. Regional (spinal, epidural, caudal) versus general anesthesia in preterm infants undergoing herniorraphy in early infancy (Review). Cochrane Database Syst Rev. 2015;6:CD003669.

\section{Publisher's Note}

Springer Nature remains neutral with regard to jurisdictional claims in published maps and institutional affiliations.
Ready to submit your research? Choose BMC and benefit from:

- fast, convenient online submission

- thorough peer review by experienced researchers in your field

- rapid publication on acceptance

- support for research data, including large and complex data types

- gold Open Access which fosters wider collaboration and increased citations

- maximum visibility for your research: over $100 \mathrm{M}$ website views per year

At BMC, research is always in progress.

Learn more biomedcentral.com/submissions 